\title{
Seasonal variability of maternal effects in European hake Merluccius merluccius
}

\author{
C. García-Fernández ${ }^{1, *}$, R. Domínguez-Petit ${ }^{2}$, N. Aldanondo ${ }^{3}$, F. Saborido-Rey ${ }^{1}$ \\ ${ }^{1}$ Institute of Marine Research (IIM-CSIC), 36208 Vigo, Spain \\ ${ }^{2}$ Spanish Institute of Oceanography (IEO), 36390 Vigo, Spain \\ ${ }^{3}$ AZTI-Tecnalia, Marine Research Unit, 20110 Pasaia, Spain
}

\begin{abstract}
Maternal attributes may influence the quantity and quality of offspring and hence, their survival. We evaluated the seasonal variability in maternal effects on developing oocytes and larvae of European hake Merluccius merluccius from the southern stock. Females were collected in 10 different years between 1999 and 2017 in the 3 spawning seasons identified in NW Spain (winter-spring, summer and autumn). Five indices of reproductive trait characteristics (batch fecundity $[\mathrm{BF}]$, relative fecundity $[\mathrm{RBF}]$, oocyte dry weight [ODW], oocyte diameter [OD] and oocyte lipid droplet diameter [ODD]) and 4 indices of maternal effects (total length [TL], gutted weight, hepatosomatic index [HSI] and Fulton's $K$ ) were analysed. Additionally, larvae were sampled in 2017 during winter-spring and summer spawning peaks to study seasonal variability in their growth and allometry. The results revealed maternal effects on offspring attributes (for both oocytes and larvae) that differed among seasons in terms of productivity and oocyte quality; more and likely better-quality oocytes were produced in the winter-spring. BF, ODW and OD were influenced mostly by female size, ODD was related to HSI, and RBF was not influenced by any maternal attribute. The larval growth rate was similar, although summer larvae had more developed anterior body parts than winter-spring larvae. The temporal differences could be due to differences in maternal attributes and/or environmental conditions; these differences might impact larval survival and hence annual stock recruitment. A multi-year analysis of interactions between environmental conditions and maternal effects is required to understand the complex process of larval recruitment.
\end{abstract}

KEY WORDS: NW Spain $\cdot$ Reproductive potential $\cdot$ Fecundity $\cdot$ Oocyte quality $\cdot$ Larval allometry Growth

\section{INTRODUCTION}

A maternal effect is defined as the non-genetic contribution that a female confers on the phenotype of her offspring (Green 2008). In fishes, these effects are related to several maternal factors, such as age, size, condition and spawning behaviour (Reznick 1991, Spencer et al. 2014). Thus, maternal influence is not derived exclusively from genetic processes but is also derived from female characteristics, which are considered the major source of phenotypic variation at the population

\footnotetext{
*Corresponding author: cgarcia@iim.csic.es
}

level (suggested to be more influential than genotype or the extra-maternal environment), affecting offspring growth, size, survival and, eventually, population dynamics. Thus, female characteristics have an important influence on the quantity and quality of the offspring, which determine the early life stage survival rate and hence the reproductive success of the population (Green 2008, Lowerre-Barbieri 2009).

Early life stage survival is critical in the life cycles of marine fishes due to their high mortality rates (estimated at 99.9\%), which are principally driven by

(C) The authors 2020. Open Access under Creative Commons by Attribution Licence. Use, distribution and reproduction are unrestricted. Authors and original publication must be credited. 
size- and growth-selective processes (Houde 2009). This elevated mortality in marine fish eggs and larvae is triggered mostly by environmental factors, including food availability and predators (Houde 2009). However, the degree of environmental impact on the early life stages depends on attributes that are mainly determined by maternal effects. Both factors co-occur and modulate early life stages and hence are key in terms of recruitment variability (Lasker 1981, Cury \& Roy 1989, Trippel et al. 1997, SaboridoRey 2016), which is the main cause of natural variations in the abundance of marine fish populations (Hunter 1981, Houde 2008).

One of the current unifying hypotheses suggests that larger females produce not only more but also better-quality eggs and, subsequently, larger and faster-growing larvae with a higher probability of survival (Berkeley et al. 2004, Green \& McCormick 2005, Green 2008). Faster-growing larvae are less vulnerable to mortality by predation because these individuals have stronger swimming capabilities and a shorter larval period (Garrido et al. 2015). Differential allometric growth is considered an adaptive response to environmental pressures (Fuiman 1983) and defines larval shape, anatomy, physiology and finally behaviour; hence it is essential for survival (Osse \& Van Den Boogaart 1995).

European hake Merluccius merluccius (Linnaeus, 1758) is one of most important species in marine demersal ecosystems of temperate regions in the North Atlantic: it is a top predator of the demersal community and a very plastic species with a high capacity to adapt its life-history traits to changes in energy availability, environmental conditions and fishing pressure (Domínguez-Petit et al. 2008, Domínguez-Petit \& Saborido-Rey 2010). The NW Iberian Peninsula is the northernmost distribution area of the hake southern stock, and is a key spawning ground for the whole stock. Here, the hake population shows a protracted spawning season and high reproductive asynchronicity, with 3 spawning seasons: winter-spring, summer and occasionally autumn. However, there is great interannual variability in both intensity and timing (Domínguez-Petit 2007, Mehault et al. 2010). Recruitment in this stock has fluctuated strongly since records have been kept, and does not show a clear direct link to the spawning stock biomass. In this context, the differential contribution of each spawning season to annual recruitment has never been studied before, despite the relevant impact it may have on stock productivity and dynamics. Moreover, it remains unknown to what extent these 3 seasons correspond or do not corre- spond with the 3 different spawning stock components (Serrat et al. 2019).

Intra-annual variability in spawning stock attributes and offspring has been reported in European hake (Domínguez-Petit 2007, Korta et al. 2010, GarcíaFernández 2017) and in other species of the genus Merluccius (Macchi et al. 2004, Landaeta \& Castro 2012, Jansen et al. 2015). Annual and seasonal changes in oceanographic conditions also influence the location and distribution of the hake spawning area (Alvarez et al. 2001, Agostini et al. 2006, Macchi et al. 2010, Rodrigues \& Macchi 2010, Diaz et al. 2013) and the spawning time and duration (Alvarez et al. 2001, Olivar et al. 2003), affecting survivorship in early stages and recruitment (Landaeta \& Castro 2012). Additionally, fishing intensity may also affect the spawning location, timing and distribution through density-dependent effects (Macchi et al. 2005, Payá \& Ehrhardt 2005). In summary, spawning activity, stock reproductive potential, recruitment and, subsequently, stock sustainability are determined by a combination of spawning stock attributes, oceanographic conditions and harvest intensity (Scott et al. 2006, DomínguezPetit et al. 2008).

The objective of the present study was to test for the existence of seasonal variability in maternal effects and their impact on offspring performance that eventually affects stock recruitment and dynamics. For that purpose, seasonal variability in maternal, oocyte and larval features was analysed in the different spawning peaks of $M$. merluccius from the NW Iberian Peninsula.

\section{MATERIALS AND METHODS}

The study area (Fig. 1) is located on the Galician shelf (NW Iberian Peninsula), which is considered the main spawning area of the southern stock of Merluccius merluccius (Pérez \& Pereiro 1985, Sánchez \& Gil 2000).

Analyses of maternal effects were performed using 2 approaches: (1) analysing the seasonal variability in maternal attributes and their influences on oocyte production and oocyte quality and (2) analysing the seasonal differences in morphology and growth in the early larval stages.

\subsection{Maternal attributes}

Adult hake females were sampled monthly from the commercial gillnet fleets on the Galician shelf for 


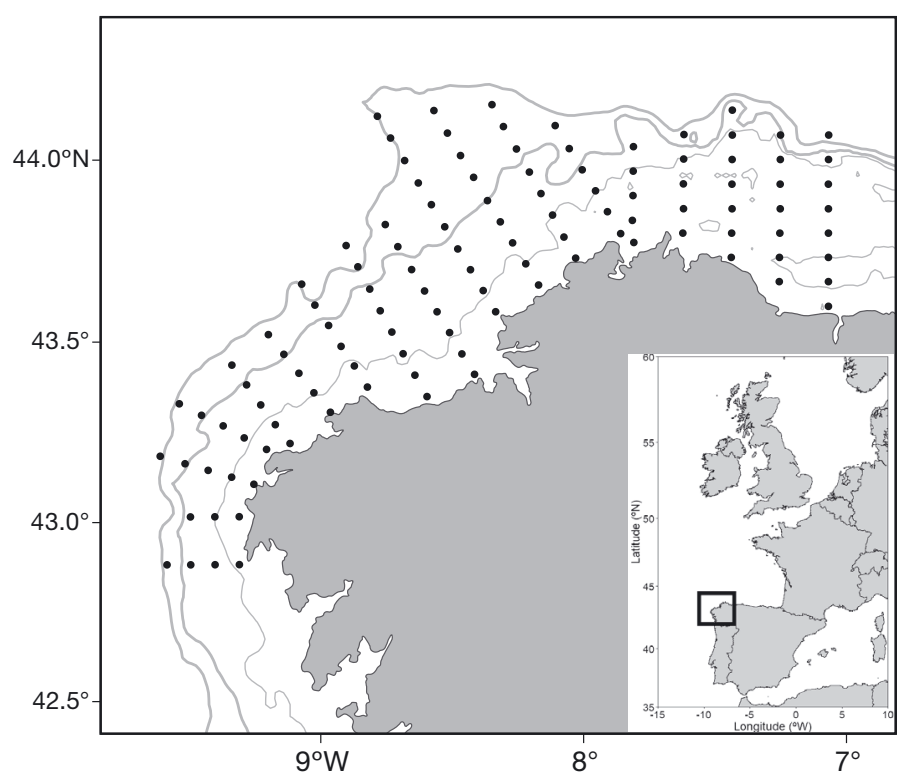

Fig. 1. Sampling area on the NW Iberian Peninsula (Galician shelf, the main spawning ground of the southern stock of Merluccius merluccius). Two surveys were performed along 144 systematic stations (black dots) on a predefined grid during early spring and summer in 2017. Grey lines: isobaths

10 years between 1999 and 2017, with a higher sampling effort during the first half of the year to cover the 2 main spawning peaks. Body metrics taken from each individual included the total length $(\mathrm{TL})(\mathrm{cm})$ and the total, gutted, gut, liver and gonad weights (g). Sex and macroscopic maturity stage data were also collected.

One ovarian lobe of each female was preserved in $4 \%$ buffered formaldehyde, embedded in paraffin, cut into $3 \mu \mathrm{m}$ sections and stained with haematoxylin-eosin for histological analysis in the laboratory. Ovary microscopic maturity stages were identified from histological sections according to Brown-Peterson et al. (2011). Only females in the actively spawning phase were used in this study, i.e. females that were close to spawning but without evidence of recent spawning (ovaries with hydrated oocytes and without recent postovulatory follicles [Day 0]). Of the 8367 females collected, 555 actively spawning females with lengths ranging between 40 and $93 \mathrm{~cm}$ were considered (see Table 1).

The maternal attributes used were $\mathrm{TL}$, gutted weight, hepatosomatic index (HSI) and Fulton's condition factor $(K)$ estimated as follows:

$$
\begin{gathered}
\text { HSI }=\frac{\text { liver weight }}{\text { gutted weight }} \times 100 \\
K=\frac{\text { gutted weight }}{\text { length }^{3}}
\end{gathered}
$$

\subsection{Oocyte production and quality}

Batch fecundity (BF), defined as the number of eggs spawned in each spawning batch, was estimated using the gravimetric method, and relative fecundity (RBF) was calculated as the ratio between $\mathrm{BF}$ and the female gutted weight. These characteristics were used as general indicators of spawning investment (Macchi et al. 2013, Ohshimo et al. 2018). Oocyte dry weight (ODW), oocyte diameter (OD) and oocyte lipid droplet diameter (ODD) were estimated in hydrated oocytes and used as proxies for oocyte quality (Kjesbu 1989, Kjorsvik et al. 1990, Brooks et al. 1997, Kennedy et al. 2007, Pavlov et al. 2009). A subsample of approximately $150 \mathrm{mg}$ of ovarian tissue was taken from the middle section of the ovary and preserved as above. To remove the formaldehyde and rehydrate the oocytes, they were cleaned with distilled water for at least $20 \mathrm{~min}$ (until OD stabilization) before proceeding to image analysis (Mehault et al. 2010). The number of hydrated oocytes per sample and the diameter of oocytes and lipid droplets $(\mu \mathrm{m})$ were obtained using image analysis ('Object J' plugin in ImageJ with a specific macro created for this purpose). We then selected 2 replicates of 50 hydrated oocytes each to estimate the mean dry weight of the hydrated oocytes by drying them for $24 \mathrm{~h}$ at $110^{\circ} \mathrm{C}$.

\subsection{Larval features}

European hake larvae were sampled during 2 different surveys carried out in winter-spring (13-29 March) and summer (17 June to 1 July) in 2017 along 114 systematic stations on a predefined grid on the Galician shelf. The stations were located every 4 nautical miles (n miles) along transects perpendicular to the shoreline, and the distance between transects was $8 \mathrm{n}$ miles (Fig. 1). Sampling was based on an adaptive design (Alvarez \& Cotano 2005) that increased the sampling effort in areas with a high presence of larvae. Ichthyoplankton samples were collected with oblique hauls using a bongo net with a mouth diameter of $60 \mathrm{~cm}(500 \mu \mathrm{m}$ mesh) at a maximum depth of $200 \mathrm{~m}$ or $5 \mathrm{~m}$ above the bottom in shallower areas. During the survey, hake larvae were identified, photographed and frozen at $-80^{\circ} \mathrm{C}$ for morphometric studies and growth analysis.

In this study, only larvae $<5000 \mu \mathrm{m}$ in standard length (SL) and in the pre-flexion stage were considered for the morphometric analysis. 


\subsubsection{Otolith analysis}

In the laboratory, larval otoliths were extracted from the saccular chamber under a binocular dissecting microscope. Once the otoliths were extracted, they were placed on glass slides that were carefully dried with absorbent paper. The otoliths were then covered with a thin layer of transparent nail varnish.

Otolith daily increments were analysed by using a light microscope coupled with an image analyser (Visilog, TNPC Software, v.5.02, Ifremer). The otoliths were read at $1000 \times$ magnification in immersion oil. All increments were counted, and the distance between increments was measured from the core to the edge of the otolith. Increments were assumed to be daily starting at the first increment. Each otolith was read twice by the same reader, and those with a difference between readings higher than $5 \%$ were rejected. A total of 117 larvae were fully processed: 73 from the winter-spring peak and 44 from the summer peak.

\subsubsection{Morphometric analysis}

Larvae images taken during the survey were used to classify the larval developmental stages and to analyse larval morphology. Only the highest-quality pictures were used, resulting in a total of 283 larvae measured: 117 from winter-spring and 166 from summer surveys. The morphometric measurements were recorded $(0.1 \mathrm{~mm})$ by using ImageJ software (https:// imagej.nih.gov/ij/). The measurements recorded are shown in Fig. 2 and were: eye diameter (ED), mouth length (ML), preorbital length (PL), head length (HL), snout to anal fin length (AL), standard length (SL), and tail height (TH), all of which were used as a condition proxy (based on Koslow et al. 1985).

\subsection{Statistical analyses}

\subsubsection{Maternal attributes and oocyte production}

Following earlier studies on hake spawning activity (Domínguez-Petit 2007, Serrat et al. 2019), 3 spawning seasons were identified: December-March (season 1), April-July (season 2) and August-November (season 3). The maternal and oocyte data were analysed according to these seasons (see Table 1) to address seasonal variability.

Data were examined for normality and heteroscedasticity, and variables were log-transformed when

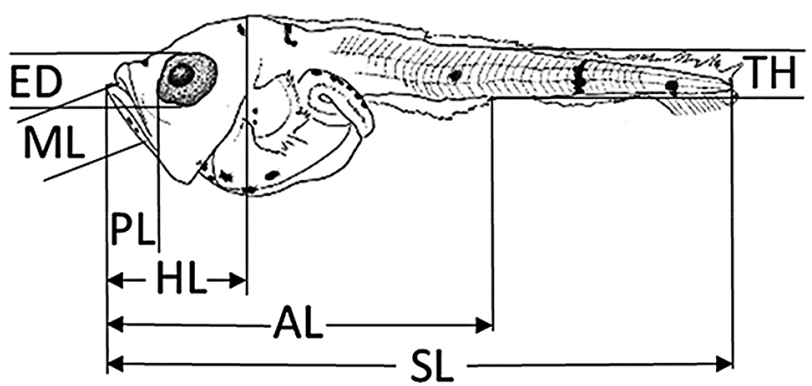

Fig. 2. Standard measurements $(\mu \mathrm{m})$ recorded for Merluccius merluccius larvae in stage 2 ; eye diameter $(\mathrm{ED})$; mouth length (ML); preorbital length (PL): distance from the tip of the snout to the eye; head length (HL): distance from the tip of the snout to the end of the head; snout to anal fin length $(\mathrm{AL})$ : distance from the tip of the snout to the end of the anal fin; standard length (SL): distance along the midline of the body from the tip of the snout to the end of the notochord; and tail height (TH): height of the body at the end of the anal fin (redrawn from Palomera et al. 2005, Copyright by CSIC)

necessary (BF and RBF). After exploratory analysis, generalized linear mixed models (GLMMs) were used to examine relationships between female attributes and their reproductive output (oocyte features). Full models were developed that included female attributes and the spawning season as fixed effects and year as a random effect because the monthly sampling intensity varied among years. Models were performed using length rather than gutted weight (although the results were similar) to avoid observed correlations between gutted weight and length, HSI and $K$ (tested with the Pearson correlation test) (Blanchard et al. 2003, Alonso-Fernández et al. 2009).

The optimal model for each response variable (oocyte quantity or quality) was selected based on the lowest Akaike's information criterion (AIC) value. Finally, pairwise comparisons among seasons were performed using Tukey's test.

\subsubsection{Larval features}

SL at age was fitted to a linear regression as:

$$
\mathrm{SL}=a+b \times \text { age }
$$

where age is the daily count of increments, $a$ is the $y$ intercept, and $b$ is interpreted as the growth rate $\left(\mu \mathrm{m} \mathrm{d}^{-1}\right)$.

In order to compare the length-at-age relationship to that in previous studies, only larvae younger than $20 \mathrm{~d}$ old were considered. The allometric growth of each larval body measurement was analysed using the allometric equation:

$$
Y=a \times X^{b}
$$


where $Y$ is each body measurement (PL, ED, ML, AL, $\mathrm{TH}$ ) and $X$ is the SL or HL. Models were fitted using linear regression after the log-transformation of all morphometric data. Based on the value of the growth coefficient, $b$, growth was classified as hypoallometric (negative allometric growth; $b$ significantly $>1$ ), isometric ( $b$ does not vary from 1 ) or hyperallometric (positive allometric growth; $b$ significantly <1) (Koumoundouros et al. 1999, Katsanevakis et al. 2007). The allometric type was tested by inspecting whether unity was within the $95 \%$ confidence interval of the slope estimates. Tukey's test was used to assess differences in growth allometry between the winter-spring and summer peaks.

All statistical analyses were conducted using $\mathrm{R}$ software version 3.4.3 (R Core Team 2017) using a significance level of $\alpha=0.05$.

\section{RESULTS}

\subsection{Maternal attributes}

The mean, standard deviation and minimum and maximum values estimated for all maternal attributes and morphological indices analysed in actively spawning females by season are listed in Table 1. The mean TL and the length range decreased during the year $(58.7,57.5$ and $55.2 \mathrm{~cm}$ for seasons 1 , 2 and 3, respectively, Fig. 3A), although they did not differ significantly $\left(\mathrm{p}_{\mathrm{S} 1-\mathrm{S} 2}=0.183, \mathrm{p}_{\mathrm{S} 1-\mathrm{S} 3}=\right.$ $\left.0.073, \mathrm{p}_{\mathrm{S} 2-\mathrm{S} 3}=0.336\right)$. Similarly, the mean gutted weight (1194.9, 1126.0 and $1161.7 \mathrm{~g}$ for seasons 1, 2 and 3, respectively; Fig. 3B) did not differ among seasons $\left(\mathrm{p}_{\mathrm{S} 1-\mathrm{S} 2}=0.297, \mathrm{p}_{\mathrm{S} 1-\mathrm{S} 3}=0.915, \mathrm{p}_{\mathrm{S} 2-\mathrm{S} 3}=\right.$ 0.906), as expected, given the observed high cor-

Table 1. Total length, gutted weight, Fulton's condition factor $(K)$ and hepatosomatic index (HSI) of actively spawning female Merluccius merluccius (mean $\pm \mathrm{SD}$ [n]) sampled per season. Each season includes 4 months corresponding to 1 spawning peak over 10 years of sampling between 1999 and 2017. S1: Season 1 (December-March); S2: Season 2 (April-July); S3: Season 3 (August-November). (-) Data not available

\begin{tabular}{|c|c|c|c|c|c|}
\hline Season & Year & Total length (cm) & Gutted weight (g) & $K$ & HSI \\
\hline \multirow[t]{10}{*}{$\mathrm{S} 1$} & 1999 & $54.33 \pm 8.51(9)$ & $1185.56 \pm 631.01(9)$ & $0.69 \pm 0.05$ & - \\
\hline & 2000 & $56.80 \pm 7.29$ & $1241.00 \pm 504.35$ & $0.65 \pm 0.06$ & - \\
\hline & 2002 & $50.75 \pm 5.30(2)$ & $872.50 \pm 251.02(2)$ & $0.66 \pm 0.01(2)$ & $4.87 \pm 0.52(2)$ \\
\hline & 2003 & $54.02 \pm 5.05(65)$ & $1009.13 \pm 306.31(65)$ & $0.63 \pm 0.05(65)$ & $4.42 \pm 1.30(65)$ \\
\hline & 2004 & $53.00 \pm 2.98(8)$ & $950.00 \pm 217.98(8)$ & $0.63 \pm 0.05(8)$ & $5.21 \pm 1.22(8)$ \\
\hline & 2005 & $56.27 \pm 4.75(22)$ & $1110.13 \pm 264.36(22)$ & $0.61 \pm 0.04(22)$ & $4.20 \pm 1.78(22)$ \\
\hline & 2007 & $55.97 \pm 6.54(20)$ & $1150.38 \pm 362.81(20)$ & $0.65 \pm 0.05$ & $4.96 \pm 1.70(20)$ \\
\hline & 2011 & $61.22 \pm 3.18$ & $1491.50 \pm 246.78$ & $0.64 \pm 0.02(5)$ & $5.83 \pm 1.96(5)$ \\
\hline & 2012 & $61.50 \pm 9.32(86)$ & $1479.61 \pm 456.71$ & $0.60 \pm 0.09(86)$ & $3.89 \pm 1.16(86)$ \\
\hline & 2017 & $62.38 \pm 9.55(76)$ & $1555.25 \pm 434.99(76)$ & $0.62 \pm 0.05(76)$ & $5.01 \pm 1.29(76)$ \\
\hline Total S1 & & $58.73 \pm 8.62(298)$ & $1194.87 \pm 424.60(298)$ & $0.63 \pm 0.06(298)$ & $4.59 \pm 1.41(284)$ \\
\hline \multirow[t]{10}{*}{$\mathrm{S} 2$} & 1999 & $50.56 \pm 4.88(9)$ & $922.50 \pm 290.31(9)$ & $0.67 \pm 0.05(9)$ & - \\
\hline & 2000 & $46.83 \pm 2.14(6)$ & $695.83 \pm 65.83(6)$ & $0.68 \pm 0.04(6)$ & - \\
\hline & 2002 & - & - & - & - \\
\hline & 2003 & $58.08 \pm 4.75(65)$ & $1220.95 \pm 351.55(65)$ & $0.61 \pm 0.09(65)$ & $4.83 \pm 1.13(65)$ \\
\hline & 2004 & - & - & - & - \\
\hline & 2005 & $54.54 \pm 8.77(16)$ & $999.63 \pm 396.62(16)$ & $0.60 \pm 0.07(16)$ & $3.16 \pm 0.12(16)$ \\
\hline & 2007 & $53.83 \pm 3.01(7)$ & $960.63 \pm 174.68(7)$ & $0.61 \pm 0.04(7)$ & $3.61 \pm 1.25(7)$ \\
\hline & 2011 & - & - & - & - \\
\hline & 2012 & $59.56 \pm 8.44(55)$ & $1034.67 \pm 87.64(55)$ & $0.63 \pm 0.02(72)$ & $2.50 \pm 1.65(55)$ \\
\hline & 2017 & $58.19 \pm 7.11(72)$ & $1193.55 \pm 367.38(72)$ & $0.63 \pm 0.02(72)$ & $4.40 \pm 1.65(72)$ \\
\hline Total S2 & & $57.51 \pm 7.22(230)$ & $1125.96 \pm 362.02(230)$ & $0.62 \pm 0.08(230)$ & $4.42 \pm(215)$ \\
\hline \multirow[t]{10}{*}{ S3 } & 1999 & $52.00(1)$ & $950.00(1)$ & $0.68(1)$ & - \\
\hline & 2000 & - & - & - & - \\
\hline & 2002 & - & - & - & - \\
\hline & 2003 & $54.92 \pm 4.62(6)$ & $1032.87 \pm 245.28(6)$ & $0.61 \pm 0.03(6)$ & $6.28 \pm 1.09(6)$ \\
\hline & 2004 & $51.70 \pm 2.97(2)$ & $926.45 \pm 253.21(2)$ & $0.66 \pm 0.07(2)$ & $3.86(2)$ \\
\hline & 2005 & $55.06 \pm 4.20(12)$ & $1201.57 \pm 362.61$ & $0.70 \pm 0.08(12)$ & $5.71 \pm 0.86(12)$ \\
\hline & 2007 & - & - & - & - \\
\hline & 2011 & - & - & - & - \\
\hline & 2012 & $53.60 \pm 13.58(2)$ & $1122.00 \pm 769.33(2)$ & $0.67 \pm 0.01(2)$ & $6.85 \pm 1.41(2)$ \\
\hline & 2017 & $59.58 \pm 8.11(4)$ & $1426.00 \pm 586.49$ & $0.65 \pm 0.02(4)$ & $5.84 \pm 0.58(4)$ \\
\hline Total S3 & & $55.23 \pm 5.57(27)$ & $1161.74 \pm 391.83(27)$ & $0.67 \pm 0.06(27)$ & $5.93 \pm(26)$ \\
\hline
\end{tabular}




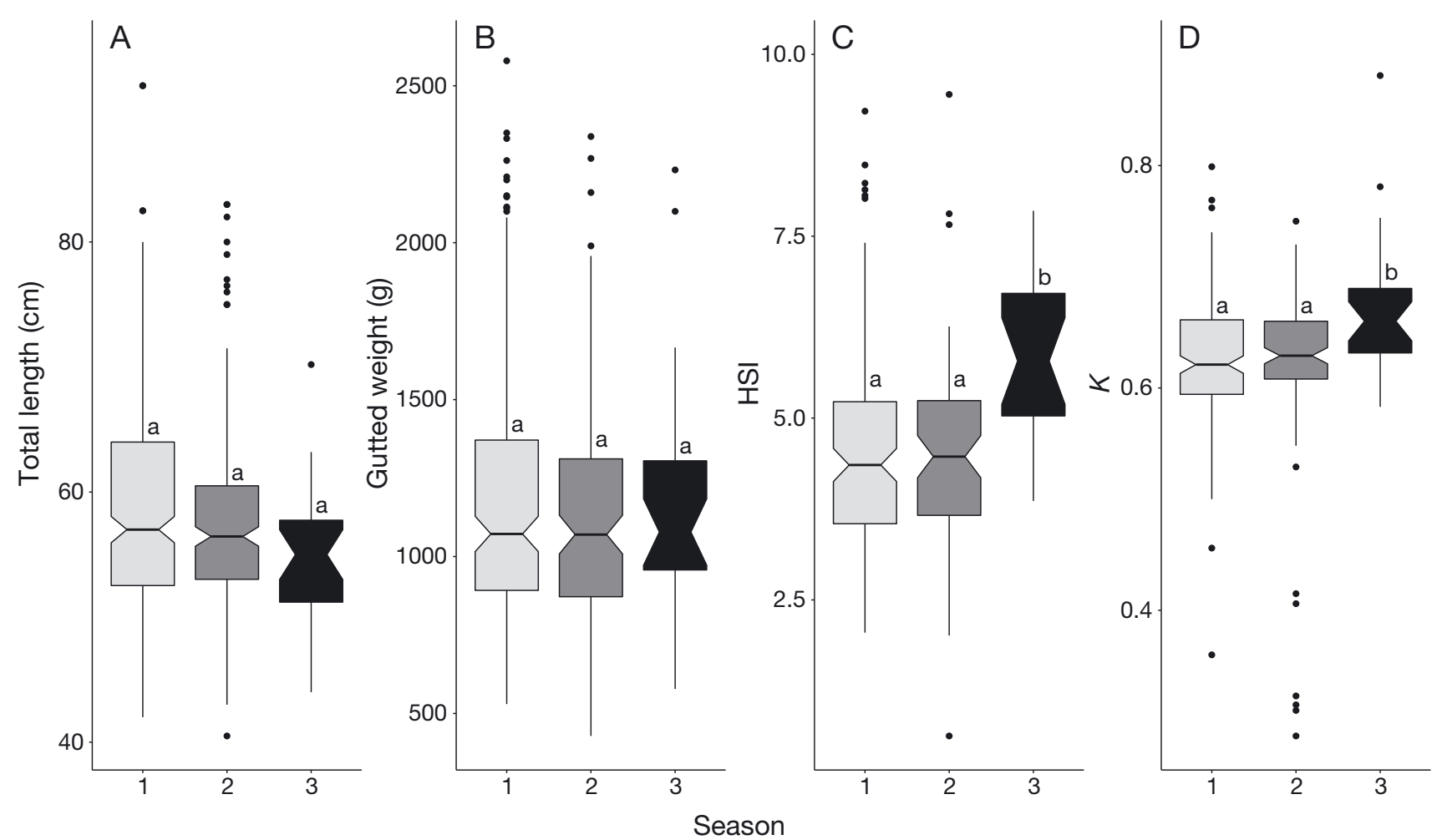

Fig. 3. Merluccius merluccius maternal attribute distributions among seasons 1, 2 and 3: (A) total length, (B) gutted weight, (C) hepatosomatic index (HSI) and (D) Fulton's condition factor $(K)$. The line in the box is the mean value, the top of the box is the third quartile (Q3/75th percentile), the bottom of the box is the first quartile (Q1/25th percentile), the solid vertical lines are the $\mathrm{SE}$ and the dots are outliers; letters above boxes indicate significant differences among groups

relation with female size $(\mathrm{r}=0.930, \mathrm{n}=334, \mathrm{p}<$ $0.001)$.

In contrast, both condition indices, HSI and $K$, were significantly higher in season 3 than in the other seasons (HSI: $\mathrm{p}_{\mathrm{S} 1-\mathrm{S} 2}=0.697, \mathrm{p}_{\mathrm{S} 1-\mathrm{S} 3}<0.001, \mathrm{p}_{\mathrm{S} 2-\mathrm{S} 3}<0.001$; $\left.K: \mathrm{p}_{\mathrm{S} 1-\mathrm{S} 2}=0.749, \quad \mathrm{p}_{\mathrm{S} 1-\mathrm{S} 3}<0.01, \mathrm{p}_{\mathrm{S} 2-\mathrm{S} 3}<0.01\right)$ (Fig. 3C,D).

\subsection{Oocyte production and quality}

The average BF and RBF were significantly higher in season $1(p<0.01)$ but did not differ between seasons 2 and 3 (Fig. 4A,B). Both BF and RBF were modelled by using maternal attributes and spawning season as explanatory variables. For BF, the best model included only length and season as fixed effects and explained $63 \%$ of the variability. According to the model, TL showed a significant effect on BF ( $p<$ 0.001) (Fig. 5A) that followed a power relationship. A post hoc Tukey test showed that the BF-TL relationship differed significantly $(p<0.001)$ among all seasons. BF was consistently higher at all lengths in winter-spring (season 1) and lower in summer (season 2) (Fig. 5A). The slope of the BF-TL relationship was not significantly different from 3 in seasons 1 and 3, indicating a proportional increase in fecundity with body mass. However, this coefficient was significantly lower than 3 in season 2, indicating that larger females had a lower fecundity than expected. The lack of larger females sampled in this period may explain this result. Consistent with the above results, RBF was not related to female size, nor to any other maternal attributes. The best model only included the significant effect of season, which explained $33 \%$ of the variability. Thus, larger females did not spawn more eggs per gram in each batch than smaller females. Regarding oocyte quality proxies, the ODW was significantly higher in season 1 than in seasons 2 and 3 (Fig. 4C). The best GLMM was built with TL and season as fixed effects. This model explained $43 \%$ of the total variability, and there was a positive and significant relationship between TL and ODW $(p<0.001)$. The post hoc Tukey test indicated that the ODW-TL relationship differed significantly between seasons $(p<0.001)$ except between seasons 2 and 3 $(\mathrm{p}=0.276)$ (Fig. 5B).

On the other hand, females released larger oocytes in season 1; these oocytes were similar in size to the eggs released in season 3 but significantly different 


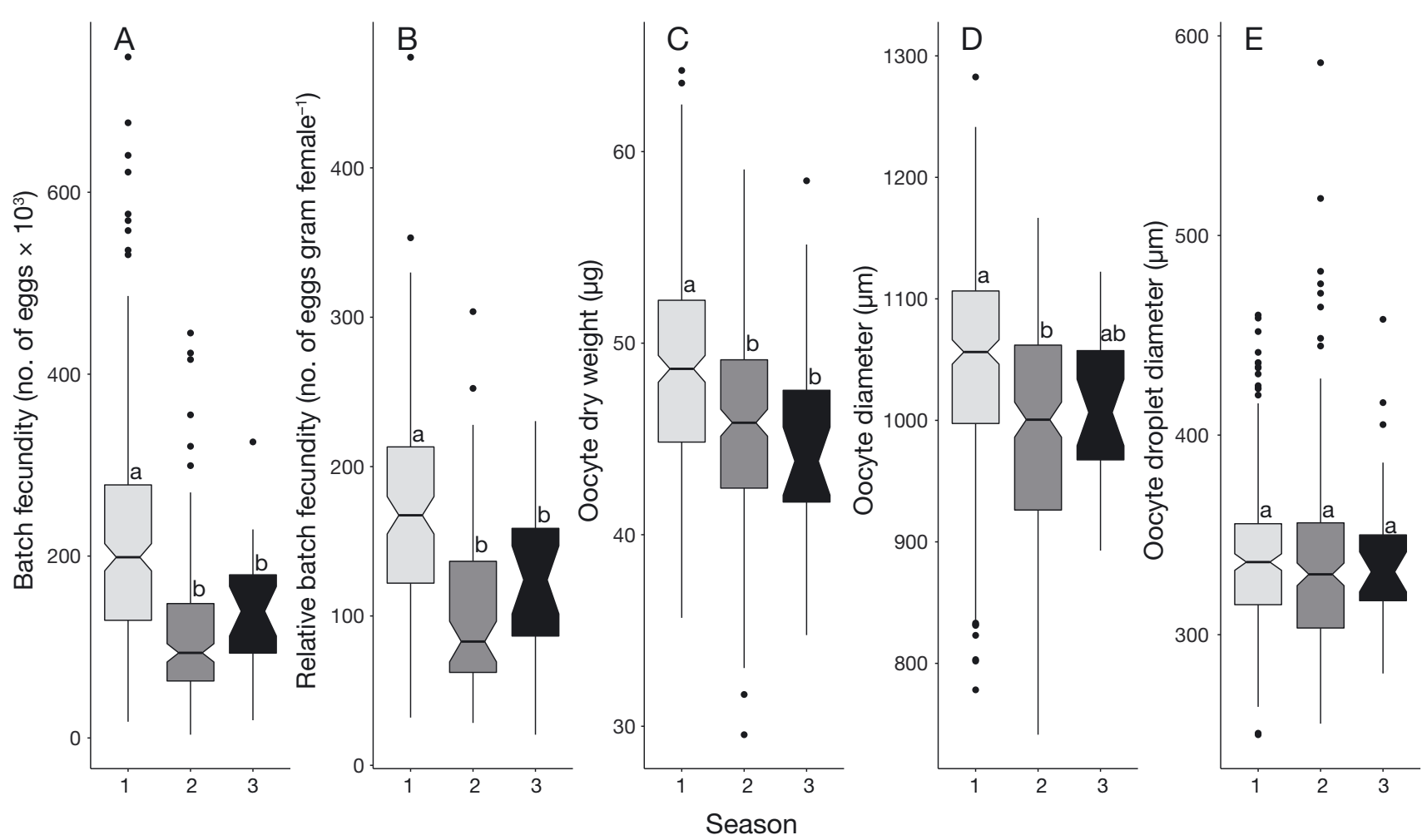

Fig. 4. Merluccius merluccius oocyte attribute distribution among seasons 1, 2 and 3: (A) batch fecundity, (B) relative batch fecundity; (C) oocyte dry weight; (D) oocyte diameter and (E) oocyte droplet diameter. The line in the box represents the mean value, and the solid vertical lines represents the standard error; letters above boxes indicate significant differences among groups

from the oocytes in season 2 (Fig. 4D). The best model included TL and season. This model explained $31 \%$ of the OD variability. There was a positive and significant relationship between OD and TL $(\mathrm{p}<$ 0.01) (Fig. 5C). The OD-TL relationship in season 1 differed significantly from that in the other 2 seasons $(p<0.001)$, although those in season 2 and season 3 did not differ from each other $(p=0.089)$.

Finally, the ODD did not differ significantly among seasons (Fig. 4E). The optimal model included only HSI as a fixed effect $\left(r^{2}=0.36\right)$. Therefore, there was no significant relationship between female size and ODD, but ODD was positively and significantly related to HSI ( $p<0.001$ ) (Fig. 5D). No significant differences among seasons in the HSI-ODD relation were observed.

\subsection{Larval features}

\subsubsection{Otolith analysis}

Only larvae in the pre-flexion stage were used in this analysis. Larval size ranged from 2070 to $5350 \mu \mathrm{m}(0$ to $18 \mathrm{~d}$ ) in the winter-spring survey and from 2100 to $5000 \mu \mathrm{m}$ ( 1 to $18 \mathrm{~d}$ ) in the summer survey. The larval growth rate did not differ significantly between the surveys during the prehatching stage $(p=0.109)$. Data from both surveys were pooled for growth modelling, which resulted in a linear model:

$$
\begin{gathered}
\mathrm{SL}=2378.80+138.5 \times \text { age } \\
\left(\mathrm{r}^{2}=0.82, \mathrm{p}<0.001, \mathrm{n}=100 ; \text { Fig. } 6\right)
\end{gathered}
$$

Hence, the mean growth rate of hake larvae was $139 \mu \mathrm{m} \mathrm{d}^{-1}$.

\subsubsection{Allometric features}

Fig. 7 shows the relationships between morphometric features and SL or HL. All of them fit well to the allometric equation and showed significant relationships (Table 2). However, only the growth of ED and AL with SL differed significantly between surveys $(p<0.05$, Fig. 7). Growth was isometric for the PL-HL, ML-HL, HL-SL, and TH-SL relationships as well as for the ED-SL relationship during the second spawning season (Table 2). The rest of the allometric coefficients differed significantly from 1. PL, ML and AL (in both surveys) presented a positive allometry with 

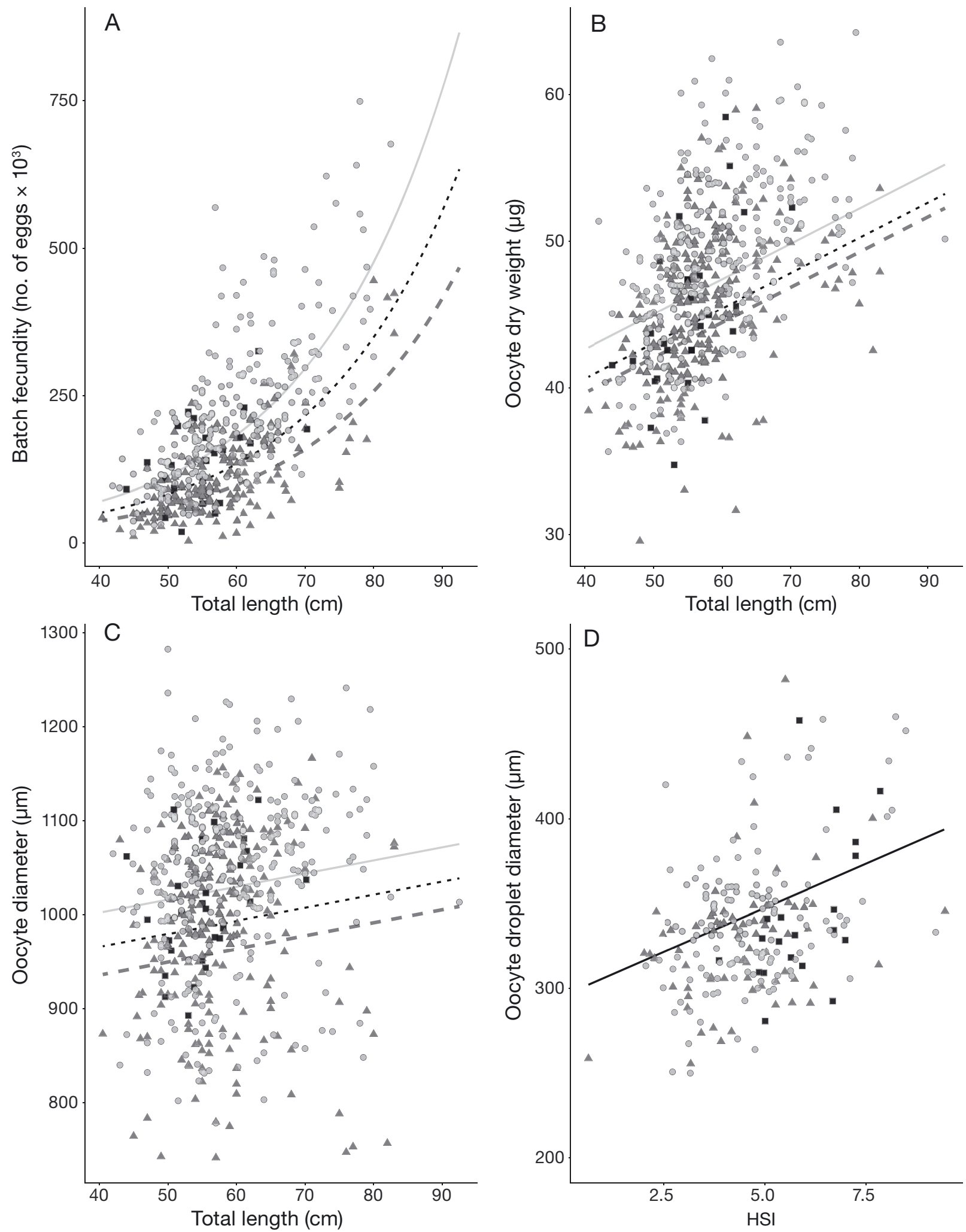

Fig. 5. Relationships by season in European hake on the Galician coast: (A) estimated batch fecundity-total length, (B) oocyte dry weight-total length, (C) oocyte diameter-total length and (D) oocyte lipid droplet diameter-hepatosomatic index (HSI). Circles and solid light grey lines represent the winter-spring season, triangles and grey dashed lines represent the summer season, and squares and dotted dark grey lines represent the autumn season. When the relationship was similar among seasons, data were pooled and are represented by a single black solid line 


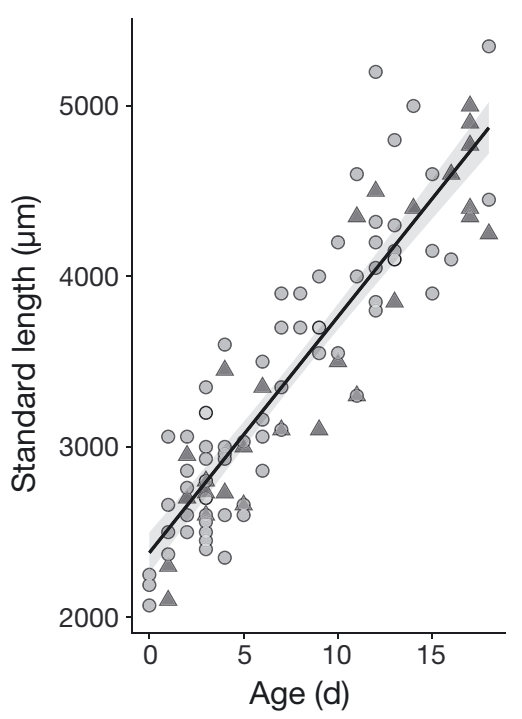

Fig. 6. Length-at-age relationship for European hake larvae for the first $20 \mathrm{~d}$ of life. Linear regression with pooled data for both surveys represented by the black line. Circles: winterspring spawning peak; triangles: summer spawning peak; grey shading: confidence interval (CI) of the prediction from the linear regression model

respect to SL, while 2 other morphometric features showed negative allometry: ED with HL and with SL (the latter only in the first survey).

\section{DISCUSSION}

Annual recruitment in fish populations has often been associated with complex combinations of environmental and maternal effects, where stock reproductive potential (SRP) plays a pivotal role in recruitment success (Chambers \& Waiwood 1996, Marteinsdottir \& Steinarsson 1998, Saborido-Rey 2016). In this study, we analysed the seasonality of the maternal influence on offspring attributes and discuss the potential impact it could have on recruitment. Our case study, the southern stock of European hake, is particularly suitable for this analysis, as it shows a very protracted spawning duration, with 3 spawning seasons (Domínguez-Petit et al. 2008, DomínguezPetit \& Saborido-Rey 2010, Mehault et al. 2010).

Female size and condition have been reported as the main factors defining SRP in exploited species (Trippel 1999). However, our results show no differences in female size among spawning seasons. Given the annual length-based growth rate for this stock (ca. $19 \mathrm{~cm}$, Piñeiro et al. 2007), significant seasonal differences were expected if the spawning stock remained the same throughout the year. Therefore, either the females spawning in each season are different (sug- gesting several spawning components, as hypothesized by Serrat et al. 2019), or maturation occurs throughout the year and not during a specific season, and hence maturing females (i.e. first-time spawners, with smaller size) are found in each season.

On the other hand, the condition indices (HSI and $K$ ) were significantly higher in the autumn, suggesting the production of better-quality eggs and larvae during this season (Scott et al. 1999, Rodrigues et al. 2018). Seasonal variations in fish energy storage and hence fish condition are usually related to seasonal changes in diet, food consumption and the balance of assimilated energy allocations to the growthreproduction trade-off (Jobling 1995, Pedersen \& Hislop 2001, Alonso-Fernández \& Saborido-Rey 2012), especially in 'income breeder' species (Beuchel et al. 2013). In summer and early autumn, hake likely devote more time to foraging and growing, thus reducing their reproductive investment (as observed by the lower fecundity in summer and autumn) and storing energy. However, only HSI influenced offspring features (ODD), although $K$ was reported as relevant in other hake species (Macchi et al. 2006). $K$ is often considered an overbroad and simplistic descriptor of the nutritional state, while HSI has been considered to have a strong influence on reproductive variables (Marteinsdottir \& Begg 2002), including in hake (Macchi et al. 2006, Leonarduzzi et al. 2014). Rodrigues et al. (2018) reported the influence of HSI on ODD in Argentine hake Merluccius hubbsi.

European hake is an 'income breeder' species, i.e. its reproduction is mostly supported by recently acquired, or incoming, energy, and it is less dependent on energy reserves than other species (DomínguezPetit \& Saborido-Rey 2010). In income breeder species, long-term energy storage $(K)$ is less important than short-term storage in the liver (AlonsoFernández \& Saborido-Rey 2012, Zudaire et al. 2013). The liver plays an important role in vitellogenesis, especially in final oocyte maturation (Wiegand 1996, Patiño \& Sullivan 2002). Accordingly, our results suggest that HSI is relevant in the formation of the oocyte lipid droplet. The lipid droplet is an important component of the quality of the released egg, often related to its buoyancy and survivorship (Babin et al. 2007), and it plays an important role as an energetic reserve during initial larval development (Wiegand 1996, Rodgveller et al. 2012). Eggs with larger lipid droplets can hatch larger larvae with higher survival rates and, in theory, promote higher recruitment rates (Rijnsdorp \& Vingerhoed 1994, Trippel 1998).

Fecundity is generally considered to increase with female size. Nevertheless, in recent decades, several 

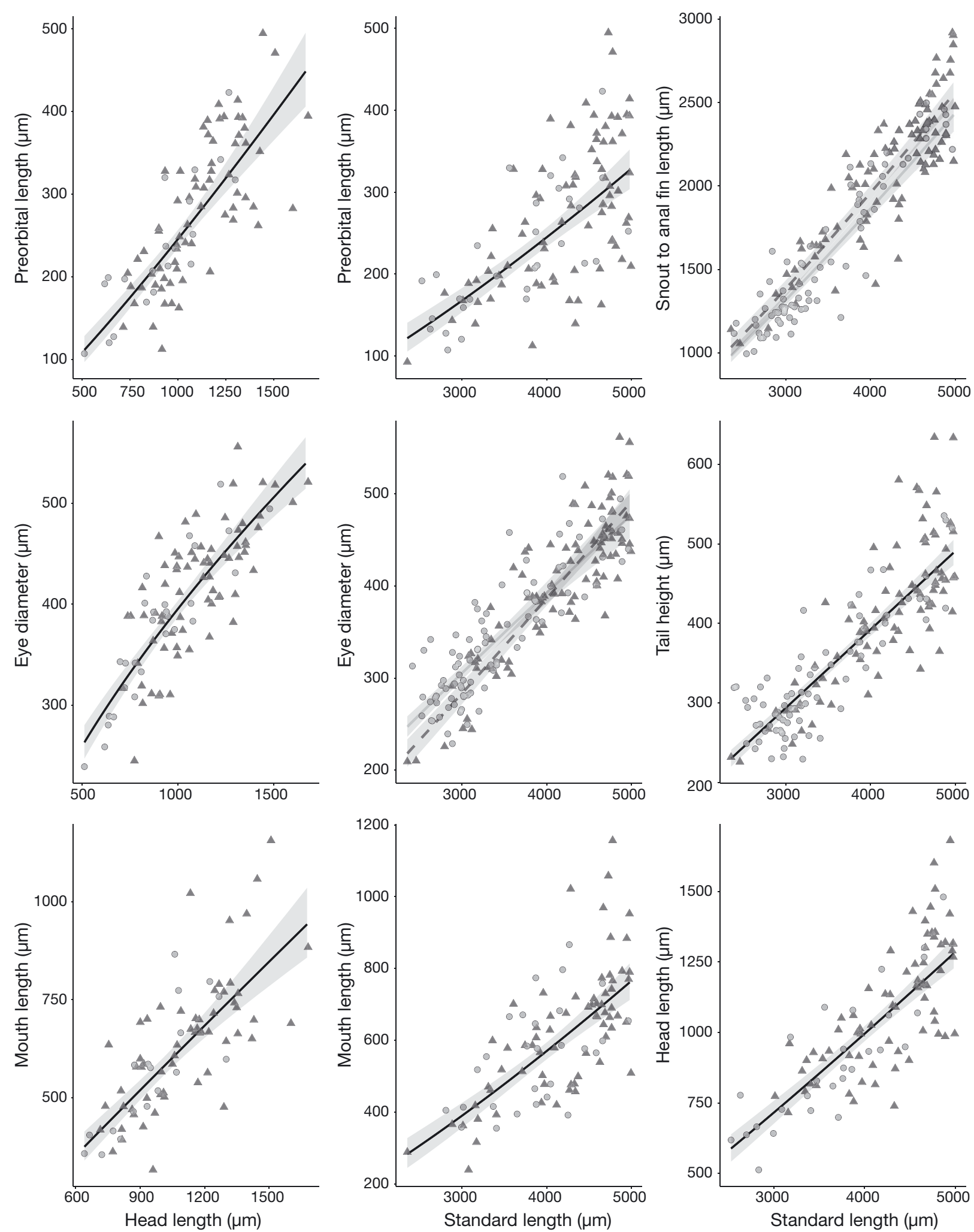

Fig. 7. Predicted allometric relationships between morphometric measures and standard length or head length (log-transformed data) for European hake larvae. Circles, triangles: winter-spring and summer surveys, respectively. When the allometric relationship was similar between surveys, data were pooled and are represented by a black solid line. If the allometric relationship differed between surveys, the solid light grey line represents the winter-spring survey, and the grey dashed line represents the summer survey. Grey shading: confidence interval (CI) of the prediction from the linear regression model 
Table 2. Parameters of allometric relationships between each morphometric trait and standard length (SL) or head length (HL) of Merluccius merluccius larvae fitted to a potential equation $Y=a X^{b}$ (where $b$ is the growth coefficient and $a$ is the intercept). CI $b$ : coefficient interval of the growth coefficient; $n$ : number of measurements of each larval trait; Allo: allometry for each trait ++ indicates positive allometry, - indicates negative allometry and * indicates isometry); PL: preorbital length; ED: eye diameter; ML: mouth length; AL: snout to anal fin length; TH: tail height. When the growth coefficient differed between seasons, allometric analysis was performed separately (S1: survey 1, S2: survey 2)

\begin{tabular}{|lccccccc|}
\hline Allometric relationship & $b$ & CI $b$ & $a$ & $\mathrm{r}^{2}$ & $\mathrm{n}$ & $\mathrm{p}$ & Allo \\
\hline PL-SL & 1.32 & $1.06-1.58$ & -5.44 & 0.48 & 108 & $<0.001$ & + \\
PL-HL & 1.18 & $0.99-1.37$ & -2.65 & 0.63 & 88 & $<0.001$ & $*$ \\
ED-SL (S1) & 0.87 & $0.76-0.99$ & -1.26 & 0.79 & 88 & $<0.001$ & - \\
ED-SL (S2) & 1.08 & $0.80-1.36$ & -2.99 & 0.79 & 93 & $<0.05$ & $*$ \\
ED-HL & 0.61 & $0.52-0.70$ & 1.78 & 0.66 & 99 & $<0.001$ & - \\
ML-SL & 1.32 & $1.06-1.58$ & -4.61 & 0.51 & 96 & $<0.001$ & + \\
ML-HL & 0.96 & $0.77-1.15$ & -0.28 & 0.58 & 77 & $<0.001$ & $*$ \\
AL-SL (S1) & 1.21 & $1.12-1.29$ & -2.47 & 0.87 & 73 & $<0.001$ & + \\
AL-SL (S2) & 1.21 & $1.13-1.38$ & -2.42 & 0.87 & 90 & $<0.01$ & + \\
TH-SL & 1.00 & $0.91-1.10$ & -2.36 & 0.74 & 162 & $<0.001$ & $*$ \\
HL-SL & 1.14 & $0.98-1.31$ & -2.58 & 0.66 & 100 & $<0.001$ & $*$ \\
& & & & & & & \\
\hline
\end{tabular}

spring survival for hake eggs and larvae due to the higher possibility of spawning in favourable conditions (Field et al. 2008).

Hake show seasonal maternal influence not only in egg production but also in egg quality (ODW and OD). Earlier studies detected similar seasonal differences only in OD but not in ODW (Mehault et al. 2010). If we assume that the dry weight, diameter and lipid droplet diameter of hydrated oocytes are proportional to those attributes in released eggs, we can conclude that the eggs laid in winterspring are of higher quality than the summer and autumn eggs. Egg quality, especially size and weight, has an important influence on early life stage growth and survival (Marteinsdottir \& Steinarsson 1998, Trippel 1998, Rideout et al. 2005). On the one hand, ODW

studies have shown that fecundity increases disproportionally with female size and condition (Marshall et al. 1999, Lambert \& Dutil 2000), indicating an increase in reproductive potential and maternal influence (Marshall et al. 2003, Saborido-Rey et al. 2011, Barneche et al. 2018). However, our results on hake show that BF increases with size proportionally to body mass (i.e. a slope of 3), which is also reflected in the lack of a relationship between female size and RBF. Nevertheless, although BF can be used as a proxy for reproductive effort, it is questionable to use it as a proxy for egg production because the realized fecundity is the product of $\mathrm{BF}$ and the number of batches produced by a female within a season; the latter is known to vary with female size and condition, as well among seasons (Hunter \& Leong 1981, Alheit 1993, Zwolinski et al. 2001, Mehault et al. 2010). In hake, the duration of spawning increases with female size; as a result, egg production and reproductive potential are higher in larger females (Serrat et al. 2019). It is known that in batch spawners, larger fish produce more egg batches over a longer period in each season (Hixon et al. 2014). Notably, the duration of spawning does not change throughout the year (Serrat et al. 2019), but BF does change throughout the year. This reflects a particular energy allocation balance among seasons and female sizes. Thus, it seems that the realized egg production is influenced by maternal effects, but female size affects the number of batches rather than the number of eggs released per batch. This fact is important because it increases the chances for off- is linked to the amount of energy available for the embryo and larvae (Nissling et al. 1994, Vallin \& Nissling 2000, Mehault et al. 2010). On the other hand, OD is correlated with egg density and buoyancy (Kjesbu et al. 1992). Thus, egg quality may affect larval survival through the regulation of not only physiological capacities but also offspring distribution (Vallin \& Nissling 2000, Saborido-Rey et al. 2003, Almatar et al. 2004). Finally, lipid droplets have been described as playing an important role in larval growth and survival in other hake species (Macchi et al. 2013), but they did not show a seasonal difference in our study. Seasonal variability in oocyte attributes could be an adaptation to different seasonal environments, i.e. it does not reflect differences in quality but is an adaptive response. In this sense, Chambers \& Leggett (1996) analysed the egg size variability in 309 North Atlantic marine fishes and showed that the variation depends on the spawning season of the stock, i.e. it depends on timing.

The SRP of European hake in the southern stock increases with female size, but also shows a seasonal pattern. The maximum female size, sampled in this study $(92.5 \mathrm{~cm})$ is considerably lower than the historical maximum size recorded for this species $(140 \mathrm{~cm}$, Choen et al. 1990). Although this difference could be due to the sampling bias derived from gear selectivity, it is more likely to be the result of size truncation in the hake population. Fisheries are usually sizeselective, targeting larger fish and eroding the size and age structure of the population; this promotes a 
demographic structure dominated by younger age classes and jeopardizes the positive effects of sizerelated reproductive traits on offspring survival, i.e. it erodes the SRP (Scott et al. 1999, Birkeland \& Dayton 2005, Hsieh et al. 2010). Hake have been largely overexploited (Murua 2010), a circumstance that is exacerbated by their differential sex growth rate, which produces a strongly skewed sex ratio, i.e. virtually all fish larger than $45 \mathrm{~cm}$ are females. Consequently, demographic truncation intensifies the importance of these maternal effects to population persistence, and can alter the population regulatory processes that determine hake population dynamics, with important management implications (Hidalgo et al. 2012, Cerviño et al. 2013) .

Despite the observed seasonal differences in egg quality, the larval growth rate among seasons was similar. This growth pattern could be related to the water temperature at depths inhabited by the European hake larvae, between 50 and $200 \mathrm{~m}$ (Coombs \& Mitchell 1982, Sabatés 2004). At these depths, the temperature did not change critically in 2017, with means of $13.2^{\circ} \mathrm{C}$ (in the winter-spring survey) and $13.5^{\circ} \mathrm{C}$ (in the summer survey) at the sampled stations where hake larvae were present. The observed growth rate (139 $\mu \mathrm{m} \mathrm{d}^{-1}$ in younger larvae) is lower than in the northern stock $\left(140-150 \mu \mathrm{m} \mathrm{d}^{-1}\right.$ for larvae younger than $20 \mathrm{~d}$ old, Alvarez \& Cotano 2005) or the Mediterranean stock (150-190 $\mu \mathrm{m} \mathrm{d}^{-1}$ for larvae younger than $26 \mathrm{~d}$ old, Palomera et al. 2005). One important feature in hake larval growth is that during the first $12 \mathrm{~d}$ after hatching, growth in length is reduced in favour of higher proportional development of the anterior part of the body, resulting in strong allometric growth (Palomera et al. 2005) that is likely related to hake physiology and behaviour (Osse \& Van Den Boogaart 1995). This suggests that length at age is not the best proxy of larval development in the first days of life, and allometric analysis should be performed instead. Our results revealed that larvae hatching in summer show a more developed anterior part (larger AL) than larvae hatching in winterspring. This difference may imply better condition of summer larvae, but it could also be an adaptation to summer environmental conditions.

Larval fish feeding success is affected by environmental conditions, i.e. the concentration and type of prey, water turbulence, light conditions and temperature (Hunter 1981, MacKenzie et al. 1994, Morote et al. 2011). The development of organs related to feeding, and hence, the type and number of potential prey, primarily takes place during the first days of life (Osse \& Van Den Boogaart 1995) and determines the survival of larvae after mouth opening. In this study, mouth size exhibited a noticeable increase (hyperallometric relationship with SL) during the first days; this is likely related to the predation capacity of larvae, as Merluccius larvae start feeding on prey that are much larger than those eaten by larvae of other species (Hunter 1981).

Eye development is important because marine fish larvae are visual feeders (Hunter 1981). Eye size is an approximation of visual ability in fishes because the larger the eye is, more photoreceptors it has, and hence, the more capacity it has to detect small objects (Fernald 1988, Lee \& Stevens 2007, Yahaya et al. 2011). The ED presented isometric growth in summer larvae and hypoallometric growth in larvae from winter-spring, although the eye was larger at hatching in winter-spring than in summer larvae. These differences could be explained by the environmental characteristics. According to our CTD data (not presented in this manuscript), in summer, the photosynthetically active radiation in the study area is significantly higher than that in winter-spring, i.e. plankton production is higher in summer, and consequently, the turbidity of the water column is higher. Considering that summer larvae are exposed to a more turbid environment than winter-spring larvae, rapid eye development would be an adaptation for better vision in this context, which could increase its competitive capacity. This study should be repeated over several years to corroborate this hypothesis.

We have demonstrated the existence of maternal effects on fecundity, OD, ODW and ODD. However, the larger oocytes produced in winter-spring actually did not result in larger larvae in this season. Larval fitness seems to be more correlated with lipid droplet diameter (Green 2008), and more dependent on female condition than on other factors. Several studies on early life stages have demonstrated a positive correlation between the ODD and larval survival because the lipid droplet provides a longer endogenous feeding period that allows more time to arrive at feeding areas before starvation, and a higher capability of avoiding predators (Miller et al. 1988, Kennedy et al. 2007, Green 2008).

At the population level, the existence of multiple spawning seasons likely increases the probability that the offspring will find optimum conditions for growth and survival, which ultimately impacts reproductive success and recruitment (Scott et al. 2006, Alonso-Fernández \& Saborido-Rey 2011). Overall, multiple spawning seasons can be seen as a tactic to increase the reproductive potential of the stock. However, it is still unknown whether these different 
spawning seasons are the consequence of multiple spawning periods of a single spawning stock or if they are the product of the presence of different spawning components within the stock (Serrat at al. 2019). In other areas and species of the genus Merluccius, the existence of several spawning peaks is associated with different stocks or sub-stocks (Bustos et al. 2007, Helser \& Alade 2012). Nevertheless, differences in female size distribution (despite not being significant here), in combination with recent insights into oocyte dynamics in this stock, suggest, although not conclusively, the existence of 3 spawning components (Serrat et al. 2019). Understanding spawning dynamics is fundamental for stock assessment, management and exploitation. It is critical to ascertain the relative contribution of each spawning season to annual recruitment. Most recruits likely come from the winter-spring spawning season, considering the higher egg production observed, whereas summer and autumn spawning could act as a buffer stock production to take advantage of fluctuating environmental conditions. To test this hypothesis, studies on the daily growth of recruits $(1 \mathrm{yr}$ old) to determine their dates of birth and the proportional contribution of each spawning peak to annual recruitment are recommended.

\section{CONCLUSIONS}

This study demonstrates the existence of maternal effects in European hake. Female size and condition have a direct, although not strong, influence on egg quality and productivity. These maternal effects and oocyte traits show a complex seasonal pattern, but generally result in higher oocyte production and larger oocytes in winter-spring than in other spawning seasons. Larval development also differs among seasons, with summer larvae presenting larger body sizes and more developed anterior parts of the body (directly related to their survival). These variations are the result of the interaction between maternal effects and environmental conditions during each spawning season. The seasonal differences in egg production and quality, maternal effects and larval development may have profound consequences for the fate of annual recruitment, and hence for management and exploitation, and should be further studied.

Acknowledgements. C.G.F. was supported by a Predoctoral Fellowship from the Fundación Tatiana Pérez de Guzmán el Bueno, as well as the support by Do*MaR (PhD program). The study was carried out with financial support from the
DREAMER project (CTM2015-66676-C2-1-R) funded by the Spanish National Research Program. Special thanks are extended to Lucía Sánchez Ruiloba for the image analysis macro development and help with the larval measurements; Paula Rodriguez, Jorge Pastoriza, Sonia Rábade and Cristina Nine for help in the laboratory; Alex Alonso for help in statistics; and the Group of Fisheries Ecology from the Institute of Marine Research (IIM-CSIC) for their support. Finally, we thank Gustavo Macchi and María Korta for their suggestions for improving the study.

\section{LITERATURE CITED}

Agostini VN, Francis RC, Hollowed AB, Pierce SD, Wilson C, Hendrix AN (2006) The relationship between Pacific hake (Merluccius productus) distribution and poleward subsurface flow in the California Current System. Can J Fish Aquat Sci 63:2648-2659

Alheit J (1993) Use of the daily egg production method for estimating biomass of clupeoid fishes: a review and evaluation. Bull Mar Sci 53:750-767

Almatar SM, Lone KP, Abu-Rezq TS, Yousef AA (2004) Spawning frequency, fecundity, egg weight and spawning type of silver pomfret, Pampus argenteus (Euphrasen) (Stromateidae), in Kuwait waters. J Appl Ichthyol 20: 176-188

Alonso-Fernández A, Saborido-Rey F (2011) Maternal influence on the variation of the reproductive cycle of Trisopterus luscus (Gadidae). Cienc Mar 37:619-632

Alonso-Fernández A, Saborido-Rey F (2012) Relationship between energy allocation and reproductive strategy in Trisopterus luscus. J Exp Mar Biol Ecol 416-417:8-16

Alonso-Fernández A, Vallejo AC, Saborido-Rey F, Murua H, Trippel EA (2009) Fecundity estimation of Atlantic cod (Gadus morhua) and haddock (Melanogrammus aeglefinus) of Georges Bank: application of the autodiametric method. Fish Res 99:47-54

Alvarez P, Cotano U (2005) Growth, mortality and hatchdate distributions of European hake larvae, Merluccius merluccius (L.), in the Bay of Biscay. Fish Res 76:379-391

Alvarez P, Motos L, Uriarte A, Egaña J (2001) Spatial and temporal distribution of European hake, Merluccius merluccius (L.), eggs and larvae in relation to hydrographical conditions in the Bay of Biscay. Fish Res 50:111-128

Babin PJ, Cerdà J, Lubzens E (2007) The fish oocyte: from basic studies to biotechnological applications. Springer, Dordrecht

Barneche DR, Robertson DR, White CR, Marshall DJ (2018) Fish reproductive-energy output increases disproportionately with body size. Science 360:642-645

Berkeley SA, Chapman C, Sogard SM (2004) Maternal age as a determinant of larval growth and survival in a marine fish, Sebastes melanops. Ecology 85:1258-1264

* Beuchel JS, Marschall EA, Aday DD (2013) Energy allocation patterns in a multiple spawning sunfish: evidence for an income-based reproductive strategy. Fish Manag Ecol 20:508-517

* Birkeland C, Dayton PK (2005) The importance in fishery management of leaving the big ones. Trends Ecol Evol 20:356-358

Blanchard JL, Frank KT, Simon JE (2003) Effects of condition on fecundity and total egg production of eastern Scotian Shelf haddock (Melanogrammus aeglefinus). Can J Fish Aquat Sci 60:321-332 
Brooks S, Tyler CR, Sumpter JP (1997) Egg quality in fish: What makes a good egg? Rev Fish Biol Fish 7:387-416

Brown-Peterson NJ, Wyanski DM, Saborido-Rey F, Macewicz BJ, Lowerre-Barbieri SK (2011) A standardized terminology for describing reproductive development in fishes. Mar Coast Fish 3:52-70

Bustos CA, Balbontín F, Landaeta MF (2007) Spawning of the southern hake Merluccius australis (Pisces: Merlucciidae) in Chilean fjords. Fish Res 83:23-32

Cerviño S, Domínguez-Petit R, Jardim E, Mehault S, Piñeiro C, Saborido-Rey F (2013) Impact of egg production and stock structure on MSY reference points and its management implications for southern hake (Merluccius merluccius). Fish Res 138:168-178

Chambers RC, Leggett WC (1996) Maternal influences on variation in egg sizes in temperate marine fishes. Am Zool 36:180-196

* Chambers RC, Waiwood KG (1996) Maternal and seasonal differences in egg size and spawning characteristics of captive Atlantic cod, Gadus morhua. Can J Fish Aquat Sci 53:1986-2003

Choen DM, Inada T, Iwamoto T, Scialabba N (1990) Gadiform fishes of the world (Order Gadiformes). An annotated and illustrated catalogue of cods, hakes, grenadiers and other gadiform fishes known to date. FAO Species Catalogue. FAO, Rome

* Coombs SH, Mitchell CE (1982) The development rate of eggs and larvae of the hake, Merluccius merluccius (L.) and their distribution to the west of the British Isles. ICES J Mar Sci 40:119-126

Cury P, Roy C (1989) Optimal environmental window and pelagic fish recruitment success in upwelling areas. Can J Fish Aquat Sci 46:670-680

Diaz MV, Arano MF, Pájaro M, Aristizábal EO, Macchi GJ (2013) The use of morphological and histological features as nutritional condition indices of Pagrus pagrus larvae. Neotrop Ichthyol 11:649-660

Domínguez-Petit R (2007) Study of reproductive potential of Merluccius merluccius in the Galician Shelf. PhD dissertation, University of Vigo

Nomínguez-Petit R, Saborido-Rey F (2010) New bioenergetic perspective of European hake (Merluccius merluccius L.) reproductive ecology. Fish Res 104:83-88

Domínguez-Petit R, Korta M, Saborido-Rey F, Murua $\mathrm{H}$, Sainza M, Piñeiro C (2008) Changes in size at maturity of European hake Atlantic populations in relation with stock structure and environmental regimes. J Mar Syst 71: 260-278

Fernald RD (1988) Aquatic adaptations in fish eyes. In: Atema J, Fay RR, Popper AN, Tavolga WN (eds) Sensory biology of aquatic animals. Springer, New York, NY, p 435-466

Field JG, Moloney CL, du Buisson L, Jarre A, Stroemme T, Lipinski MR, Kainge P (2008) Exploring the BOFFFF hypothesis using a model of southern African deepwater hake (Merluccius paradoxus). In: Tsukamoto K, Kawamura T, Takeuchi T, Beard TD Jr, Kaiser MJ (eds) Fisheries for global welfare and environment, 5th World Fisheries Congress 2008, Tokyo, p 17-26

Fuiman LA (1983) Growth gradients in fish larvae. J Fish Biol 23:117-123

García-Fernández C (2017) Maternal effects on oocyte dynamic and production in European hake. MSc thesis, Ghent University

Garrido S, Ben-Hamadou R, Santos AMP, Ferreira S and others (2015) Born small, die young: intrinsic, size-selective mortality in marine larval fish. Sci Rep 5:17065

*Green BS (2008) Maternal effects in fish populations. Adv Mar Biol 54:1-105

* Green BS, McCormick MI (2005) Maternal and paternal effects determine size, growth and performance in larvae of a tropical reef fish. Mar Ecol Prog Ser 289:263-272

*Helser TE, Alade L (2012) A retrospective of the hake stocks off the Atlantic and Pacific coasts of the United States: uncertainties and challenges facing assessment and management in a complex environment. Fish Res 114:2-18

*Hidalgo M, Rouyer T, Bartolino V, Cerviño S and others (2012) Context-dependent interplays between truncated demographies and climate variation shape the population growth rate of a harvested species. Ecography 35: $637-649$

*Hixon MA, Johnson DW, Sogard SM (2014) BOFFFFs: on the importance of conserving old-growth age structure in fishery populations. ICES J Mar Sci 71:2171-2185

*Houde ED (2008) Emerging from Hjort's shadow. J Northwest Atl Fish Sci 41:53-70

Houde ED (2009) Recruitment variability. In: Jakobsen T, Fogarty MJ, Megrey BA, Moksness E (eds) Fish reproductive biology: implications for assessment and management. Wiley, New York, NY, p 91-171

* Hsieh CH, Yamauchi A, Nakazawa T, Wang WF (2010) Fishing effects on age and spatial structures undermine population stability of fishes. Aquat Sci 72:165-178

Hunter J (1981) Feeding ecology and predation of marine fish larvae. In: Lasker R (ed) Marine fish larvae: morphology ecology and relation to fisheries. Washington Sea Grant Program, University of Washington Press, Seattle, WA, p 33-77

Hunter JR, Leong R (1981) The spawning energetics of female northern anchovy, Engraulis mordax. Fish Bull 79:215-230

Jansen T, Kainge P, Singh L, Wilhelm M and others (2015) Spawning patterns of shallow-water hake (Merluccius capensis) and deep-water hake ( $M$. paradoxus) in the Benguela Current Large Marine Ecosystem inferred from gonadosomatic indices. Fish Res 172:168-180

Jobling M (1995) Environmental biology of fishes. Chapman \& Hall, London

Katsanevakis S, Thessalou-Legaki M, Karlou-Riga C, Lefkaditou E, Dimitriou E, Verriopoulos G (2007) Informationtheory approach to allometric growth of marine organisms. Mar Biol 151:949-959

Kennedy J, Geffen AJ, Nash RDM (2007) Maternal influences on egg and larval characteristics of plaice (Pleuronectes platessa L.). J Sea Res 58:65-77

Kjesbu OS (1989) The spawning activity of cod, Gadus morhua. J Fish Biol 34:195-206

Kjesbu OS, Kryvi H, Sundby S, Solemdal P (1992) Buoyancy variation in eggs of Atlantic cod (Gadus morhua L.) in relation to chorion thickness and egg size: theory and observations. J Fish Biol 41:581-599

Kjorsvik E, Mangor-Jensen A, Holmefjord I (1990) Egg quality in fishes. Adv Mar Biol 26:71-113

Korta M, Domínguez-Petit R, Murua H, Saborido-Rey F (2010) Regional variability in reproductive traits of European hake Merluccius merluccius L. populations. Fish Res 104:64-72

Koslow JA, Brault S, Dugas J, Fournier RO, Hughes P (1985) Condition of larval cod (Gadus morhua) off southwest Nova Scotia in 1983 in relation to plankton abundance and temperature. Mar Biol 86:113-121 
Koumoundouros G, Divanach P, Kentouri M (1999) Ontogeny and allometric plasticity of Dentex dentex (Osteichthyes: Sparidae) in rearing conditions. Mar Biol 135: 561-572

Lambert Y, Dutil JD (2000) Energetic consequences of reproduction in Atlantic cod (Gadus morhua) in relation to spawning level of somatic energy reserves. Can J Fish Aquat Sci 57:815-825

Landaeta MF, Castro LR (2012) Seasonal and annual variation in Chilean hake Merluccius gayi spawning locations and egg size off central Chile. Prog Oceanogr 92-95:166-177

Lasker R (1981) The role of a stable ocean in larval fish survival and subsequent recruitment. In: Lasker R (ed) Marine fish larvae: morphology ecology and relation to fisheries. Washington Sea Grant Program, University of Washington Press, Seattle, WA, p 81-87

Lee S, Stevens CF (2007) General design principle for scalable neural circuits in a vertebrate retina. Proc Natl Acad Sci USA 104:12931-12935

Leonarduzzi E, Rodrigues KA, Macchi GJ (2014) Proximate composition and energy density in relation to Argentine hake females (Merluccius hubbsi) morphometrics and condition indices. Fish Res 160:33-40

Lowerre-Barbieri S (2009) Reproduction in relation to conservation and exploitation of marine fishes. In: Jamieson BGM (ed) Reproductive biology and phylogeny of fishes (agnathans and bony fishes), Vol 8B. Science Publishers, Enfield, NH, p 371-394

*Macchi GJ, Pájaro M, Ehrlich M (2004) Seasonal egg production pattern of the Patagonian stock of Argentine hake (Merluccius hubbsi). Fish Res 67:25-38

Macchi GJ, Pájaro M, Madirolas A (2005) Can a change in the spawning pattern of Argentine hake (Merluccius hubbsi) affect its recruitment? Fish Bull 452:445-452

* Macchi GJ, Pájaro M, Militelli MI, Radovani N, Rivas L (2006) Influence of size, age and maternal condition on the oocyte dry weight of Argentine hake (Merluccius hubbsi). Fish Res 80:345-349

Macchi GJ, Martos P, Reta R, Dato C (2010) Offshore spawning of the Argentine hake (Merluccius hubbsi) Patagonian stock. Pan-Am J Aquat Sci 5:22-35

* Macchi GJ, Leonarduzzi E, Diaz MV, Renzi M, Rodrigues K (2013) Maternal effects on fecundity and egg quality of the Patagonian stock of Argentine hake (Merluccius hubbsi). Fish Bull 111:325-336

MacKenzie BR, Miller TJ, Cyr S, Leggett WC (1994) Evidence for a dome-shaped relationship between turbulence and larval fish ingestion rates. Limnol Oceanogr 39:1790-1799

* Marshall CT, Yaragina NA, Lambert Y, Kjesbu OS (1999) Total lipid energy as a proxy for total egg production by fish stocks. Nature 402:288-290

Marshall CT, Brien LO, Tomkiewicz J, Köster FW and others (2003) Developing alternative indices of reproductive potential for use in fisheries management: case studies for stocks spanning an information gradient. J Northwest Atl Fish Sci 33:161-190

Marteinsdottir G, Begg GA (2002) Essential relationships incorporating the influence of age, size and condition on variables required for estimation of reproductive potential in Atlantic cod Gadus morhua. Mar Ecol Prog Ser 235:235-256

Marteinsdottir G, Steinarsson A (1998) Maternal influence on the size and viability of Iceland cod Gadus morhua eggs and larvae. J Fish Biol 52:1241-1258
Mehault S, Domínguez-Petit R, Cerviño S, Saborido-Rey F (2010) Variability in total egg production and implications for management of the southern stock of European hake. Fish Res 104:111-122

Miller TJ, Crowder LB, Rice JA, Marschall EA (1988) Larval size and recruitment mechanisms in fishes: toward a conceptual framework. Can J Fish Aquat Sci 45: 1657-1670

Morote E, Olivar MP, Bozzano A, Villate F, Uriarte I (2011) Feeding selectivity in larvae of the European hake (Merluccius merluccius) in relation to ontogeny and visual capabilities. Mar Biol 158:1349-1361

Murua H (2010) The biology and fisheries of European hake, Merluccius merluccius, in the North-East Atlantic. Adv Mar Biol 58:97-154

Nissling A, Kryvi H, Vallin L (1994) Variation in egg buoyancy of Baltic cod Gadus morhua and its implications for egg survival in prevailing conditions in the Baltic Sea. Mar Ecol Prog Ser 110:67-74

* Ohshimo S, Sato T, Okochi Y, Ishihara Y and others (2018) Long-term change in reproductive condition and evaluation of maternal effects in Pacific bluefin tuna, Thunnus orientalis, in the Sea of Japan. Fish Res 204: 390-401

Olivar M, Quilez G, Emelianov M (2003) Spatial and temporal distribution and abundance of European hake, Merluccius merluccius, eggs and larvae in the Catalan coast (NW Mediterranean). Fish Res 60:321-331

Osse JWM, Van Den Boogaart JGM (1995) Fish larvae, development, allometric growth, and the aquatic environment. ICES Mar Sci Symp 201:21-34

Palomera I, Olivar MP, Morales-Nin B (2005) Larval development and growth of the European hake Merluccius merluccius in the northwestern Mediterranean. Sci Mar 69:251-258

* Patiño R, Sullivan CV (2002) Ovarian follicle growth, maturation, and ovulation in teleost fish. Fish Physiol Biochem 26:57-70

Pavlov DA, Emel'yanova NYG, Novikov GG (2009) Reproductive dynamics. In: Jakobsen T, Fogarty MJ, Megrey BA, Moksness E (eds) Fish reproductive biology: implications for assessment and management. Wiley, New York, NY, p 48-90

Payá I, Ehrhardt NM (2005) Comparative sustainability mechanisms of two hake (Merluccius gayi gayi and Merluccius australis) populations subjected to exploitation in Chile. Bull Mar Sci 76:261-286

* Pedersen J, Hislop JRG (2001) Seasonal variations in the energy density of fishes in the North Sea. J Fish Biol 59: 380-389

Pérez N, Pereiro FJ (1985) Reproductive aspects of hake (Merluccius merluccius L.) on the Galician and Cantabrian shelves. Bol Inst Esp Oceanogr 2:39-47

* Piñeiro C, Rey J, de Pontual H, Goñi R (2007) Tag and recapture of European hake (Merluccius merluccius L.) off the Northwest Iberian Peninsula: first results support fast growth hypothesis. Fish Res 88:150-154

R Core Team (2017) R: a language and environment for statistical computing. R Foundation for Statistical Computing, Vienna

Reznick DN (1991) Maternal effects in fish life histories. In: Dudley E (ed) The unity of evolutionary biology. Discorides Press, Portland, OR, p 780-793

Rideout RM, Rose GA, Burton MPM (2005) Skipped spawning in female iteroparous fishes. Fish Fish 6:50-72 
Rijnsdorp AD, Vingerhoed B (1994) The ecological significance of geographical and seasonal differences in egg size in sole Solea solea (L.). Neth J Sea Res 32:255-270

Rodgveller C, Lunsford CR, Fujioka JT (2012) Effects of maternal age and size on embryonic energy reserves, developmental timing, and fecundity in quillback rockfish (Sebastes maliger). Fish Bull 110:36-45

Rodrigues KA, Macchi GG (2010) Spawning and reproductive potential of the Northern stock of Argentine hake (Merluccius hubbsi). Fish Res 106:560-566

Rodrigues KA, Leonarduzzi E, Macchi GJ, Militelli MI (2018) Maternal condition, fecundity and oocyte quality of Argentine hake (Merluccius hubbsi) from the Northern stock. Fish Res 197:105-112

Sabatés A (2004) Diel vertical distribution of fish larvae during the winter-mixing period in the Northwestern Mediterranean. ICES J Mar Sci 61:1243-1252

Saborido-Rey F (2016) Fish reproduction. In: Cochran JK, Bokuniewicz HJ, Yager PL (eds) Encyclopedia of ocean sciences, 3rd edn. Academic Press, Cambridge, MA, p 232-245

Saborido-Rey F, Kjesbu OS, Thorsen A (2003) Buoyancy of Atlantic cod larvae in relation to developmental stage and maternal influences. J Plankton Res 25:291-307

Saborido-Rey F, Murua H, Macchi GJ (2011) I Simposio iberoamericano de ecología reproductiva, reclutamiento y pesquerías. Cienc Mar 37:1-12

Sánchez F, Gil J (2000) Hydrographic mesoscale structures and Poleward Current as a determinant of hake (Merluccius merluccius) recruitment in southern Bay of Biscay. ICES J Mar Sci 57:152-170

Scott B, Marteinsdottir G, Wright P (1999) Potential effects of maternal factors on spawning stock-recruitment relationships under varying fishing pressure. Can J Fish Aquat Sci 56:1882-1890

Scott BE, Marteinsdottir G, Begg GA, Wright PJ, Kjesbu OS (2006) Effects of population size/age structure, condition and temporal dynamics of spawning on reproductive

Editorial responsibility: Jana Davis,

Annapolis, Maryland, USA output in Atlantic cod (Gadus morhua). Ecol Model 191: 383-415

Serrat A, Saborido-Rey F, Garcia-Fernandez C, Muñoz M, Lloret J, Thorsen A, Kjesbu OS (2019) New insights in oocyte dynamics shed light on the complexities associated with fish reproductive strategies. Sci Rep 9:18411

Spencer PD, Kraak SBM, Trippel EA, Marshall CT (2014) The influence of maternal effects in larval survival on fishery harvest reference points for two life-history patterns. Can J Fish Aquat Sci 71:151-161

Trippel EA (1998) Egg size and viability and seasonal offspring production of young Atlantic cod. Trans Am Fish Soc 127:339-359

* Trippel EA (1999) Estimation of stock reproductive potential: history and challenges for Canadian Atlantic gadoid stock assessments. J Northwest Atl Fish Sci 25:61-81

Trippel EA, Kjesbu OS, Solemdal P (1997) Effects of adult age and size structure on reproductive output in marine fishes. In: Chambers RC, Trippel EA (eds) Early life history and recruitment in fish populations. Chapman \& Hall, London, p 31-62

Vallin L, Nissling A (2000) Maternal effects on egg size and egg buoyancy of Baltic cod, Gadus morhua: implications for stock structure effects on recruitment. Fish Res 49:21-37

*Wiegand MD (1996) Composition, accumulation and utilization of yolk lipids in teleost fish. Rev Fish Biol Fish 6: 259-286

Yahaya S, Lim LS, Shaleh SRM, Mukai Y, Anraku K, Kawamura G (2011) Ontogenetic eye development and related behavioural changes in larvae and juveniles of barramundi Lates calcarifer (Bloch). Mar Freshw Behav Physiol 44:339-348

Zudaire I, Murua H, Grande M, Bodin N (2013) Reproductive potential of yellowfin tuna (Thunnus albacares) in the western Indian ocean. Fish Bull 111:252-264

KZwolinski J, Stratoudakis Y, Sares E (2001) Intra-annual variation in the batch fecundity of sardine off Portugal. J Fish Biol 58:1633-1645

Submitted: December 5, 2019; Accepted: July 8, 2020

Proofs received from author(s): September 7, 2020 